\title{
ESTUDO DA ESTABILIDADE DE FLUIDOS NÃO- NEWTONIANOS UTILIZADOS NA PERFURAÇÃO DE POÇOS DE PETRÓLEO
}

\author{
${ }^{1}$ Alex C. de Oliveira, ${ }^{1}$ Andressa C. Oliveira, ${ }^{2}$ Flávia M. Fagundes, ${ }^{3}$ Nara B. C. Santos e \\ ${ }^{4}$ Fábio O. Arouca
${ }^{1}$ Discente do curso de graduação em Engenharia Química da UFU/MG Engenharia Química da UFU/MG
${ }^{3}$ Discente do curso de Pós-graduação da Faculdade de Engenharia da UFU/MG
${ }^{4}$ Professor da Faculdade de Engenharia Química da UFU/MG
E-mail para contato: arouca@feq.ufu.br \\ ${ }^{2}$ Bolsista Petrobras em nível doutorado, discente do curso de pós-graduação em
}

\begin{abstract}
RESUMO - O estudo da sedimentação de partículas em fluidos não-newtonianos é de extrema importância para a indústria petrolífera, visto que se assemelha ao estágio de parada técnica do processo de perfuração. Os fluidos utilizados nesse processo apresentam comportamento reológico semelhante aos fluidos não newtonianos pseudoplásticos. Uma característica desejável do processo é manter em suspensão os cascalhos produzidos na perfuração de poços de petróleo quando o fluxo de fluido de perfuração está cessado. Nesse contexto, esse trabalho objetivou avaliar a concentração volumétrica de sólidos constituintes de fluidos de perfuração em função do tempo e da posição do tubo de teste. Para isso, utilizouse a técnica de atenuação de raios gama (TARG), procedimento não destrutivo, para monitorar o perfil de sedimentação de sólidos em diferentes posições ao longo do tempo. Os resultados experimentais possibilitaram obter os teores de sólidos, e as curvas de concentração para as regiões próximas à base do tubo apresentaram comportamento de crescimento logarítmico. Dessa forma, esse estudo contribuiu para o aprimoramento do conhecimento sobre a sedimentação em fluidos não-newtonianos do tipo pseudoplásticos.
\end{abstract}

\section{INTRODUÇÃO}

O fluido de perfuração é usado como ferramenta essencial na perfuração de poços de petróleo. Segundo Thomas (2001) e Caenn et al (2011), sua importância se justifica pelas funções desempenhadas durante a operação de perfuração, tais como: transportar os cascalhos gerados até a superfície; evitar o influxo de fluidos indesejáveis (kick) e estabilizar as paredes do poço; resfriar e lubrificar a coluna de perfuração e a broca; reduzir o desgaste dos equipamentos; evitar a infiltração do fluido na rocha reservatório; e manter os sólidos em suspensão durante as paradas de circulação do fluido.

A escolha do fluido é fundamental para obter bons resultados. Deve-se operar com um fluido que apresente comportamento reológico adequado ao estágio da perfuração. Em 
situações de perfuração contínua, fluidos de baixa viscosidade são mais facilmente bombeados e o carreamento de cascalhos para a superfície também é favorecido. Por outro lado, em etapas de parada técnica, por exemplo, os sólidos fragmentos devem permanecer em suspensão a fim de evitar possíveis danos causados por sua sedimentação, como a prisão da coluna de perfuração, que aumenta o torque e o arraste, dificultando a retirada da broca. Portanto, fluidos não newtonianos pseudoplásticos são os mais empregados já que sua viscosidade aparente diminui com o aumento da tensão cisalhante (Gandelman et al., 2009).

Diante da relevância das características do fluido para o processo de perfuração de poços de petróleo, em especial da estabilidade fluidodinâmica em paradas operacionais, este trabalho objetivou monitorar o perfil de concentração volumétrica de sólidos em testes de sedimentação em batelada ao longo do tempo, em dois tipos de fluidos que se diferenciavam pela presença de um componente de formulação, denominado de produto $\mathrm{R}$, para simular as partículas obtidas na perfuração do poço.

\section{METODOLOGIA}

Com a intenção de monitorar o perfil de concentração volumétrica de sólidos em fluidos pseudoplásticos utilizados na perfuração de poços de petróleo, foram utilizados dois fluidos de perfuração sintéticos base olefina diferenciados pela presença de um simulador de partículas presentes em um processo de perfuração, denominado de produto R. Os fluidos foram formulados e cedidos pela Petrobras.

Cada fluido foi homogeneizado no agitador de hélice Ika Labortechink RW20DZMn durante 1 hora e uma amostra de $500 \mathrm{~mL}$ foi colocada no recipiente de teste, tubo de vidro de $50 \mathrm{~mm}$ de diâmetro interno.

A massa específica das suspensões e dos sólidos constituintes das mesmas foi determinada por picnometria e picnometria a gás hélio, respectivamente, e à temperatura de $25{ }^{\circ} \mathrm{C}$. O teor inicial de sólidos, por sua vez, foi obtido por triplicata no ensaio de Retorta, procedimento que as amostras são submetidas ao aquecimento de $450{ }^{\circ} \mathrm{C}$ por 1 hora, os vapores condensáveis são recolhidos em uma proveta e os sólidos restantes são quantificados por balanço de massa na célula de entrada do sistema.

A Técnica de Atenuação de Raios Gama baseia-se na diferença de intensidade do feixe de radiação antes e após a passagem pelo meio que contém a suspensão em análise, os raios gama provenientes do radioisótopo atravessam perpendicularmente o tubo de teste e incidem no detector de cintilação.

A unidade experimental era constituída pelo radioisótopo Amerício-241 $\left(\mathrm{Am}^{241}\right)$, pelo recipiente de teste, por uma plataforma elevatória que percorria a altura do tubo contento a suspensão, e pelo sistema de detecção de radiação, como ilustra a Figura 1. O monitoramento foi realizado durante o período de 90 dias. 


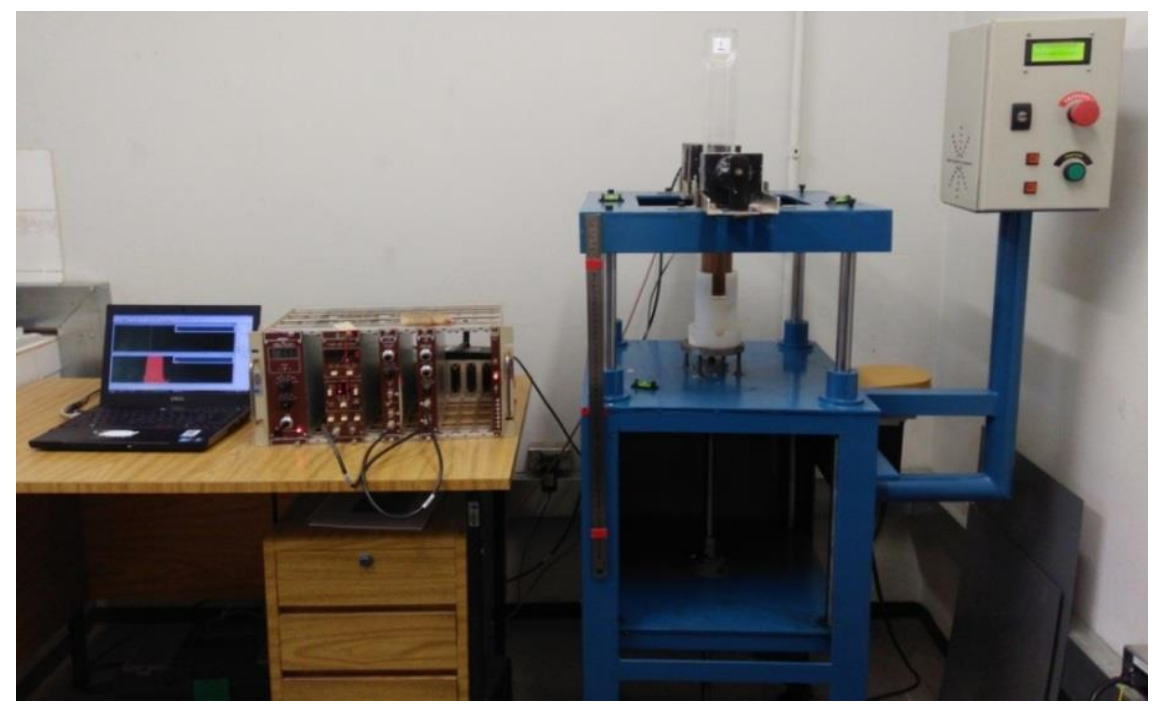

Figura 1 - Unidade experimental

A concentração volumétrica de sólidos foi obtida pela equação de Lambert (GARDNEY e ELY-JR, 1967), Equação 1. Para emprega-la, inicialmente calculou-se o parâmetro $\beta$ por meio de uma regressão linear dos valores de concentração de sólidos inicial e concentração nula de sólidos na região de líquido clarificado e suas respectivas relações logarítmicas de contagem de pulsos $\left(\ln _{0} / \mathrm{R}\right)$, como proposto por Fagundes (2015). Ressalta-se que os valores de contagem de pulsos foram previamente corrigidos pelo tempo morto, $\tau$, do sistema $\left(\tau=2,310^{-5} \mathrm{~s}\right)$.

$$
\ln \left(\frac{R_{0}}{R}\right)=\beta \cdot \varepsilon_{s}
$$

em que $R_{0}$ e $R$ são, respectivamente, as contagens corrigidas de pulsos antes e após a passagem pelo meio físico e $\varepsilon_{s}$ a concentração volumétrica de sólidos.

\section{RESULTADOS}

Os resultados da massa específica dos sólidos e das suspensões, obtidos pela picnometria e picnometria a gás hélio, respectivamente, são apresentados na Tabela 1.

Tabela 1 - Caracterização das suspensões.

\begin{tabular}{|c|c|c|}
\hline Experimento & Fluido 1 & Fluido 2 \\
\hline Massa específica dos fluidos $\left(\mathrm{g} / \mathrm{cm}^{3}\right)$ & $1,097 \pm 0,001$ & $1,1312 \pm 0,0008$ \\
\hline Massa específica dos sólidos $\left(\mathrm{g} / \mathrm{cm}^{3}\right)$ & $2,305 \pm 0,003$ & $2,206 \pm 0,003$ \\
\hline Teor de sólidos $(\%)$ & $14,1 \pm 0,6$ & $16,8 \pm 0,3$ \\
\hline
\end{tabular}

A partir dos experimentos de sedimentação em batelada dos fluidos de perfuração e da utilização da Técnica de Atenuação de Raios Gama foi possível obter as distribuições de 
concentrações volumétricas dos sólidos constituintes das suspensões em estudo em função do tempo e da posição, conforme Figura 2.
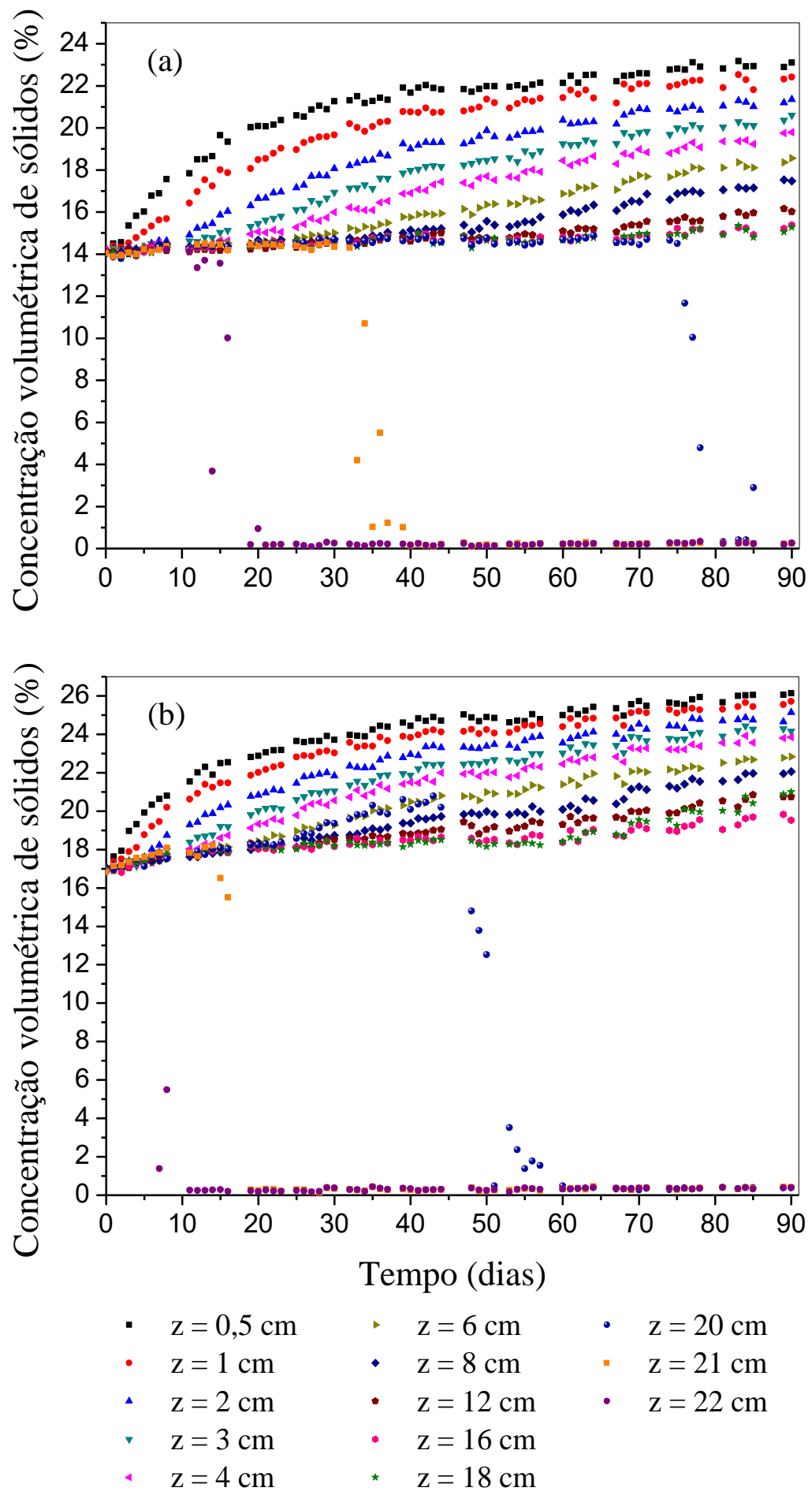

Figura 2 - Perfil de concentração volumétrica de sólidos do fluido: (a) com formulação original e (b) com a adição do produto $R$. 
Constatou-se que ambos os fluidos apresentaram concentração volumétrica de sólidos inicial constante para as diversas alturas monitoradas. Sendo que a concentração volumétrica de sólidos inicial no fluido com formulação original (Figura 2.a) era igual a 14,1 \% e a do fluido com a adição do produto $\mathrm{R}$ (Figura 2.b) era 16,8\%. O monitoramento de algumas posições não apresentou variação da concentração inicial durante todo o experimento. Sendo assim, essas posições estavam na região de sedimentação livre de partículas.

Ao final do experimento, após 90 dias de monitoramento, percebeu-se que haviam sido formadas regiões de sedimentação. Segundo Kynch (1952), próximo à base do recipiente de testes, a concentração de sólidos aumenta com o tempo até se estabilizar. Essa região é chamada de região de formação de sedimento e foi observada para ambos os experimentos. A concentração máxima de partículas no fluido com formulação original foi cerca de $23 \%$ e para o fluido com produto $\mathrm{R}$ foi cerca de $26 \%$. Em regiões intermediarias, como z $=16 \mathrm{~cm} \mathrm{e}$ $\mathrm{z}=18 \mathrm{~cm}$, a concentração praticamente não se alterou para o fluido com formulação original, enquanto no fluido com produto $\mathrm{R}$ houve um pequeno aumento.

Outra região apresentada por Kynch (1952) e que foi observada durante os experimentos foi a região isenta de sólidos, denominada de líquido clarificado. Para o fluido com a adição do produto $\mathrm{R}$ observou-se o aparecimento desta região próximo do dia 5. Já para o fluido com formulação original, a região do líquido clarificado foi estabelecida a partir do dia 10 .

Além disso, verificou-se que as curvas de concentração volumétrica de sólidos nas posições próximas à base do tubo de teste apresentaram tendência de crescimento logarítmico, o que está de acordo com o constatado por Fagundes (2015), que estudou, utilizando a mesma técnica, a sedimentação gravitacional de partículas pertencentes ao fluido de perfuração $\mathrm{Br}$ mul já utilizado em campo.

\section{CONCLUSÃO}

Com relação ao estudo experimental da sedimentação gravitacional, a utilização da fonte de radiação de Amerício ( $\mathrm{Am}^{241}$ ) na Técnica de Atenuação de Raios Gama se mostrou eficaz quando utilizada para a determinação da concentração volumétrica de sólidos nesse fluido de perfuração de poços de petróleo e para essa concentração inicial. A região de líquido clarificado se formou mais rapidamente para o fluido com adição do composto $\mathrm{R}$ em relação ao fluido com formulação original, além de contar com uma altura maior da região do líquido clarificado. A sedimentação ocorreu de forma mais intensa no fluido modificado. Sendo assim, o fluido com adição do simulador de partículas presentes em um processo de perfuração, composto R, apresentou menor estabilidade.

\section{NOMENCLATURA}

$$
\begin{aligned}
& \mathrm{g} \text { - aceleração gravitacional }\left[\mathrm{M}^{0} \mathrm{~L}^{1} \mathrm{~T}^{-2}\right] \\
& \mathrm{z} \text { - posição }\left[\mathrm{M}^{0} \mathrm{~L}^{1} \mathrm{~T}^{0}\right] \\
& \beta \text { - parâmetro da equação de Lambert }\left[\mathrm{M}^{0} \mathrm{~L}^{0} \mathrm{~T}^{0}\right] \\
& \varepsilon_{s} \text { - concentração volumétrica de sólidos }\left[\mathrm{M}^{0} \mathrm{~L}^{0} \mathrm{~T}^{0}\right] \\
& \tau \text { - tempo morto }\left[\mathrm{M}^{0} \mathrm{~L}^{0} \mathrm{~T}^{1}\right]
\end{aligned}
$$




\section{AGRADECIMENTOS}

Os autores agradecem à CAPES, ao CNPQ, à FAPEMIG, à PETROBRAS e à Faculdade de Engenharia Química da Universidade Federal de Uberlândia pelo auxílio financeiro que tornou possível a realização deste trabalho.

\section{REFERÊNCIAS}

CAENN, R.; DARLEY, H. C. H., GEORGE, R.G. Composition and Properties of Drilling and Completion Fluidos, Sixth Edition. 2011.

FAGUNDES, F. M. Estudo da estabilidade da suspensão constituinte do fluido BrMul/Petrobras. Dissertação (Mestrado em Engenharia Química) - Faculdade de Engenharia Química, Universidade Federal de Uberlândia, Uberlândia 2015.

GANDELMAN, R. A.; PINTO, G. H. V. P. Desenvolvimento de metodologia e correlações para previsão de perfil de concentração de sólidos durante a perfuração de poços de petróleo em períodos de estática. Boletim técnico da Produção de Petróleo, vol. 4 (2), 2009.

GARDNEY, R.; ELY-JR, R. Radioisotope measurement applications in engineering. Reinhold Publishing Corporation, 1967.

KYNCH, G. J. A theory of sedimentation. Transactions of the Faraday Society, p. 166-176, 1952.

MOREIRA, B. A. Estudo da sedimentação em suspensões de fluidos com características reológicas pseudoplásticas. 2014. 173f. Tese (Doutorado em Engenharia Química) Faculdade de Engenharia Química, Universidade Federal de Uberlândia, Uberlândia 2014.

THOMAS, J. E. Fundamentos de Engenharia de Petróleo. Rio de Janeiro: Interciência, PETROBRAS, 2001. 